\title{
Trust, Faith, and Commitment: A Reasoned Action Approach
}

\author{
Cam Caldwell ${ }^{1} \&$ C. Stewart Holloway ${ }^{2}$ \\ ${ }^{1}$ Alexandria, Louisiana, USA \\ ${ }^{2}$ First Baptist Church, Pineville, Louisiana, USA \\ Correspondence: Cam Caldwell, Alexandria, Louisiana, USA
}

Received: August 6, 2017

Accepted: September 15, $2017 \quad$ Online Published: September 20, 2017

doi:10.5430/bmr.v6n3p51

URL: https://doi.org/10.5430/bmr.v6n3p51

\begin{abstract}
Trust and faith have been described as similar constructs, although trust is secular and faith is religious in its basic nature. This paper compares secular trust and religious faith in context with cognitive beliefs, affective feelings, conative intentions, and actual behaviors - consistent with the theoretical framework provided by the Theory of Reasoned Action. It also identifies ten similarities between trust and faith in context with the committed actions and behaviors of the individuals who exercise that trust or faith. Finally, the paper suggests that understanding the nature of either trust or faith increases one's understanding of the other construct as well.
\end{abstract}

Keywords: Trust, Faith, Commitment, Theory of Reasoned Action, Trustworthiness, Behavior

Objective: The purposes of this paper are 1) to identify the importance of action as it relates to both trust and faith, and 2) to emphasize the powerful importance of personal commitment and a willingness to relinquish one's personal will or power to another party or to the Divine as the ultimate measure of trust or faith.

Method: This is a conceptual paper that examines and integrates the trust literature with concepts related to religious faith to demonstrate their similarities and the ultimate importance of one's behaviors in acts of either trust or faith.

Results: The paper identifies ten commonalities between trust and faith, confirms the utility of the Theory of Reasoned Action in understanding both concepts, and emphasizes the importance of one's level of commitment in action.

Conclusion: Trust and faith both are relationship based; integrate actions with beliefs, attitudes, and intentions; and demonstrate the individual level of beliefs, attitudes, and intentions in creating personal commitment and ultimately motivating personal action.

\section{Introduction}

Just as trust is the foundation of organizational effectiveness and the glue that connects interpersonal relationships, faith is the empowering force of service and self-improvement that binds a person to God. For both trust and faith the key factors that determine their ultimate impact is the degree of commitment of the individual possessing the attribute. Both trust and faith depend upon the willingness to not only comply with established standards but to embrace and be dedicated to the pursuit of desired outcomes. . . . in addition, this commitment exponentially improves organizations and changes individual lives. At the heart of trust and faith is a foundation of moral and ethical expectations about duties, responsibilities, and one's personal obligations (Mele, 2009).

The purpose of this paper is to build on the commonalities between secular trust and religious faith, and by emphasizing the importance of commitment for both attributes, to identify how an understanding of the two attributes can facilitate both interpersonal effectiveness and personal confidence in one's relationship with the Divine. In presenting this paper we incorporate a reasoned action approach - comparing trust and faith with the aid of the Theory of Reasoned Action (TRA), a well-established model for describing and clarifying the nature of individual behavior.

We begin by briefly explaining TRA as a means of understanding how behavior integrates how we think, how we feel, what we intend, and how we ultimately choose to act. Building upon that theoretical foundation, we then use TRA to examine the nature of trust and faith. Incorporating insights from the scholarly business literature and the insights of religious writers, we identify ten commonalities between trust and faith related to achieving optimal personal outcomes in achieving both secular and religious priorities. We conclude by identifying the contributions 
derived from understanding how understanding trust, faith, and commitment can assist each of us in our relationships, our organizations, and our personal lives.

\section{Foundations of TRA}

TRA examines the relationships between cognitive beliefs, emotions and attitudes, intentions to act, and actual behaviors within voluntary human action (Fishbein \& Ajzen, 2015). It assumes that voluntary behavior is an individualized subjective perception and the product of 1) cognitive beliefs and understanding of relevant information, 2) affective attitudes associated with that information - including subjective feelings based upon personal experience, and 3) individual intentions to subsequently take action based upon an inferred responsibility or duty (Hale, Householder, \& Greene, 2002). FIgure 1 identifies the relationships between beliefs, attitudes, intentions, and resulting behavior.

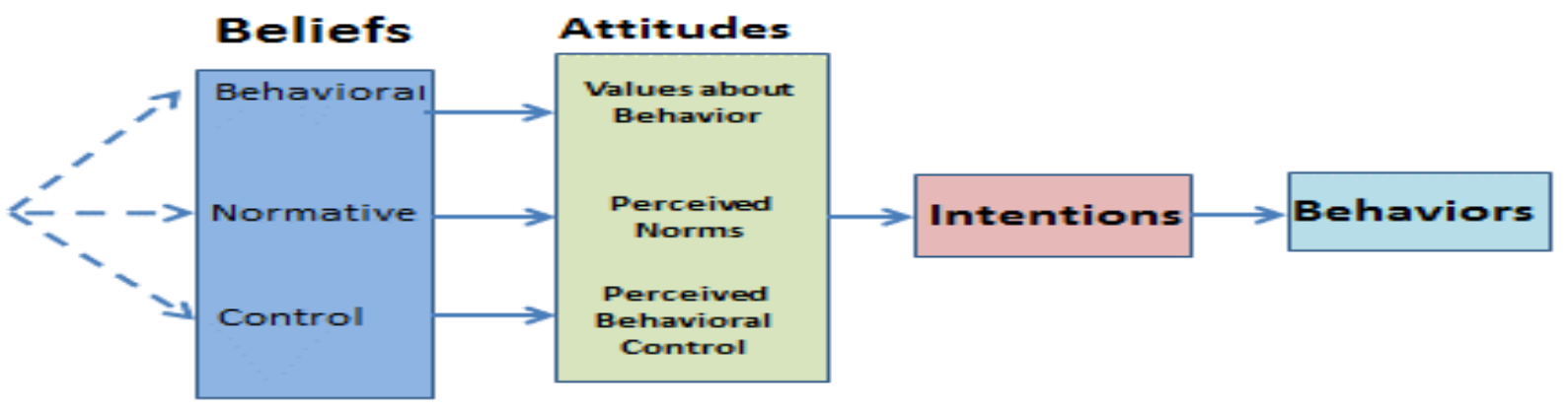

Figure 1. Theory of Reasoned Action Model

As suggested by this diagram, cognitive beliefs have three characteristics. First, they involve behavioral perceptions and how one perceives the self in context with others - including cognitive perceptions about duties owed by and to another party and consequences of behavior. Behavioral beliefs include the subjective probability that an object has a certain attribute. For example, Fishbein and Ajzen $(2015,97)$ stated that "a person may believe that physical exercise (the object) reduces the risk of heart disease (the attribute)" Second, normative beliefs are subjective cognitive perceptions about the range and standards of behavior which one's peers or social group think should or should not be considered appropriate and/or moral. Third, control beliefs are subjective cognitive perceptions about one's ability to control behavioral outcomes, such as the belief that one's exercise and diet can control their weight.

Attitudes about performing behaviors are one's subjective feelings about behaviors, norms, and one's ability to achieve a specific action. Attitudes incorporate emotional responses about an object or a person and, together with cognitive beliefs, Interrelate and form the basis for subjective perceptions about behaviors, norms, and control (Fishbein \& Ajzen, 2015). Attitudes include how one perceives the self and others and the extent which desired norms and behaviors can be affected by individual conscious choice. Beliefs and attitudes about control are influenced by one's past and how the actions of the past are perceived to have influenced the present (Hayes \& Caldwell, 2016). Thus, attitudes encompass one's perceptions about locus of control and the degree to which one influences and is influenced by outside forces.

Intentions are determined by one's integrated attitudes and beliefs about behaviors and the subjective norms that influence the desirability and rightness or wrongness about specific conduct and one's ability to perform specific behaviors (Fishbein \& Ajzen, 2015). Intentions reflect one's desire to perform specific behaviors and the stronger the intention, the greater is the effort generally made to perform a behavior or action. Bandura (1982) has reported that intentions and performance of behaviors are influenced by one's identity, self-image, and self-efficacy.

Behaviors can ultimately be best predicted by intentions, although the correlation is not perfect (Kurland, 1995). The more positive the beliefs and attitudes about a specific behavior, the more powerful and favorable the subjective norms, and the higher the perception about one's ability to control a specific behavior, the greater is the likelihood that a specific action or inaction will be performed. With regard to behavior, TRA incorporates elements of Expectancy Theory's subjective perceptions about the relative value of an outcome, one's ability to perform actions that will result in that outcome, and whether behavior is likely to generate a desired result (Brockner, Siegel, Daly, 
Tyler, \& Martin, 1997). Behaviors ultimately reflect the degree to which one believes that actions will produce desired outcomes (Fisbein \& Ajzen, 2015).

\section{Understanding Trust}

Despite hundreds of articles and books about trust, it has been a topic interpreted in a broad variety of ways by different scholars (Hosmer, 1995). TRA is helpful in understanding the nature of trust (Gullett, Canuto-Carranco, Brister, Turner, \& Caldwell, 2009; Fukuyama, 1996; Kramer \& Tyler, 1995). TRA helps to understand why trust has variously been described as a belief, attitude, intention, propensity, willingness to act, and as a behavior. In truth, trust encompasses all of these qualities but is best manifest as the relinquishing of one's personal power to another, despite the recognition of possible vulnerabilities, in the expectant hope that the other party will honor the duties of a psychological contract that exists between the parties (Gullett, et al., 2009).

By relinquishing one's personal power, an individual puts into action the degree of his/her trust in a leader and the organization (Caldwell \& Clapham, 2003). In contrast, distrust is the withholding of cooperative action and reflects an unwillingness to risk (Verhagen, Meents, \& Tan, (2006) because an individual believes that a leader and/or organization are not trustworthy (Gullett, et al., 2009). As trust increases, it reflects the confident reliance of one person on another party and that trust is manifest by trust behaviors, as shown in Figure 2.

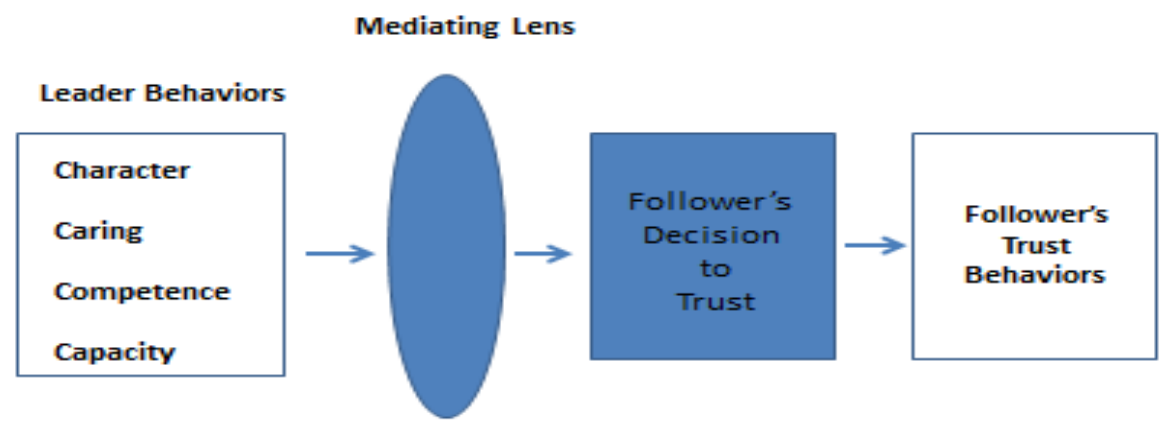

Figure 2. The Trust Process

\section{Understanding Faith}

Faith is cited in biblical and other religious writings as one's beliefs and individual actions -- despite one's doubt, uncertainty, and fear (Caldwell, Guevarra, Licona, Tayor, and McConkie, 2013). It involves relinquishing "personal choices and power to God" in the hope that so doing will demonstrate an "individual's willingness to comply with God's will" (Caldwell, Davis, \& Devine, 2008, 104). Faith recognizes that God teaches us in many ways - including by hardships and trials that often seem difficult and painful. Faith is sometimes referred to as a growing seed that can ultimately grow and mature. From the Greek, the root word from which we get faith as a noun is $\pi i \sigma \tau \iota \varsigma$ or pistis, meaning one's conviction of the truth, especially related to man's relationship to God. The Hebrew for faith is emuwn which refers to truth or faithfulness.

Some scholars have suggested that faith requires 1) a clear understanding of God and God's nature, 2) an understanding of God's expectations for man, and 3) the belief that one's life is in harmony with God's requirements. As a foundation for many religious beliefs, faith in the Divine and a willingness to trust are similar constructs, but for other religions faith requires belief in and adherence to specific doctrines, beliefs, and principles (Bowker, 2006).

\section{Commonalities between Trust and Faith}

Although trust is focused around relationships with individuals or organizations and faith is focused on a relationship with God, the concepts are alike in several ways. The following are ten commonalities that exist between secular trust and religious faith. 
1. Dependent upon a perception of trustworthiness. As indicated in Diagram 2, a follower views a leader's behaviors and determines whether the leader is trustworthy - and the decision to trust leads to trust behaviors. For faith, one's perceptions of the nature of God - that is, whether God is a loving, caring friend or a rule-setting and penalizing judge to fear - directly influences at the visceral level one's feelings about his or her relationship with the Divine. Both trust and faith are inherently ethically based and assume that behavior is tied to integrity, courage, and a sense of service as basic elements of trustworthiness (Mele, 2012).

2. Ethically-founded assuming the actor owes and is owed moral duties. Both trust and faith are replete with moral and ethical assumptions and implications (Caldwell, et al., 2013; Kurland, 1995). At the same time, the actor's assumptions about trust-related duties owed often need to be clarified to the other party and when faith is involved an individual needs to be careful not to impose upon God the individual's perceptions about ethics or justice (Caldwell, et al., 2009).

3. Measured on a continuum from reluctant obedience to devotion. Trust is measured on a continuum from reluctant compliance to enthusiastic ownership and stewardship (Hayes, et al., 2016). Faith is also a continuum ranging from self-serving obedience to a level of conviction equating with total commitment (Tilley, 2010). Figure 3, provided below, compares trust and faith on a compliance/commitment continuum.

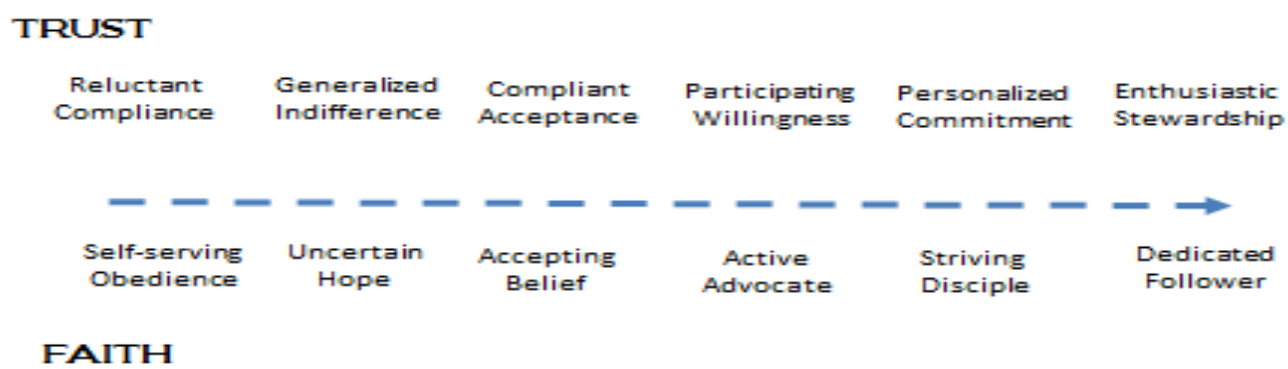

Figure 3. Trust \& Faith Compliance/Commitment Continuum

4. Based upon the perception that the other party also owes an obligation. Trust clearly implies a shared relationship with obligations owed by both parties (Gullett, et al., 2009). Faith includes the belief that a loving God knows what each individual needs to become his or her best version of self (Jones, 2017).

5. Acknowledged shared partnership with established behavioral standards. Trust is widely recognized as a key factor associated with interpersonal and organizational relationships and the relationships involved assume that quid pro quo or transactional exchange obligations exist between the parties (Jun, Rabadayi, \& Ryu, 2015; Vanneste. Puranam, \& Kretschmer, 2013). The nature of faith is that it also intended to create a partnership relationship between an individual and God, with clear behavioral standards expected for the person of faith (Parrish, 2016).

6. Centered on adding value and creating a better world. Both trust and faith are purpose driven and assume that an individual is committed as a member of an organization or as a member of a religious body to add value and create a better world (cf. De Pree, 2004). The willingness to cooperate, to take action, and to serve others is motivated by a belief that one's actions matter and that those actions can result in a positive benefit (Covey, 2004; Hayes \& Caldwell, 2016). Both rust and faith increase accountability, improve organizations, and create wealth and value for others (cf. Malloch, 2006).

7. Focused around constant learning and continuous improvement. As individuals work together, the requirements of constant learning and continuous improvement are often part of trust - and the goal of leaders is to ask others to better themselves and improve the organization (DePree, 2004). The focus of 
religion is also on constant improvement, learning, and overcoming personal obstacles that require both faith and repentance (Watson, 2013).

8. Affected by personal risk and vulnerability. The inherent risk and vulnerability associated with trust is well established (Mayer, Davis, \& Schoorman, 1995). Faith also requires the ability to act with uncertainty in honoring Divine principles that often require effort, sacrifice, and trying circumstances (Jones, 2017). Kusnner $(2001,162)$ has explained that our hopes and dreams are "beyond our power to guarantee."

9. Motivated by one's individual identity. Our identities encompass those factors that are central, distinctive, and enduring in our lives (cf. Ashworth, Shinoff, \& Rogers, 2016). For each of us we develop an "identity standard" or comparator - an ideal model of who we are and how we ought to live our lives (Burke \& Stets, 2009). This identity standard is a product of our core beliefs and values and is constantly used to assess our behaviors and actions - encouraging us to improve our actions and become our best selves (Covey, 2004). Both our decisions associated with trusting others and exercising our faith are influenced by this self-image and identity.

10. Demonstrated by choice and accountability. As individuals we are each given the right to govern our own actions and to make choices that impact ourselves, close associates, society, and the world (King, 2010). Trust and faith both are choice-based actions subject to the full range of factors that make up our beliefs, actions, and intentions in TRA (Fishbein \& Ajzen, 2010).

These ten similarities enable us to recognize that trust and faith contain commonalities in many ways and affirm that our understanding of one aid in understanding the other (Caldwell, et al., 2013).

\section{The Nature of Commitment}

Commitment transcends awareness, acknowledgement, or a fundamental belief in someone but rises to the degree to which a follower actually makes a personal investment, dedication, acceptance, and endorsement because of trust or faith. Commitment follows belief. If a person's belief does not move to commitment, (s)he cannot achieve optimal desired outcomes. Commitment reflects the degree to which TRA fully or partially is demonstrated by behavior. Thus, commitment involves more than the conscious decision to act on one's trust or faith but includes the degree to which that intention is actually carried out as individual behaviors. Related to trust, commitment reflects the degree to which an individual relinquishes personal his or her personal power and choice to a leader or organization and the degree to which his or her actions reflect personal ownership, dedication, and stewardship (Caldwell \& Hansen, 2010).

Associated with faith, the Greek word $\pi i \sigma \tau \iota \varsigma$ or pistueo is the verb often correlated with commitment. Pistueo means to believe, to trust in, to rely upon, or to commit to the charge of and captures the essence of commitment. On the faith continuum pisteuo would represent the mature "Dedicated Follower" position. Belief is a mere ascent or acknowledgement of facts. One may believe that $2+2=4$; the sun rises in the east; or that George Washington was the first President of the United States. While all of these facts are true, they do not require a commitment on the part of the "believer." One may exist in a state of belief and his life may nonetheless never be altered by that belief.

Pisteuo calls for complete commitment. Consider a sky diver. A person in early training as a skydiver may believe that (s)he can jump out of an airplane and a parachute will help to safely descend to the ground. The student may become an expert in the physics of skydiving explaining velocity, net force, resistance, acceleration, and more -- and yet never leave the classroom. Pisteuo requires that the student leave the classroom, strap on a parachute, board an airplane, ascend to 12,000 feet, and jump. A skydiver who never leaves the ground is not a skydiver. Credo, the Latin word associated with faith, literally means "I set my heart on" or "I give my heart to" and suggests the powerful and emotional commitment associated with turning our lives over to God in faith (Fowler, 1995).

A person who does not wholeheartedly commit to an organization's goals does not fully trust. A man or woman who does not demonstrate by his or her actions the commitment to live the principles of faith does not have complete faith. Both faith and trust ask a person to make a commitment without complete information. Acting on faith and trust nonetheless has been described as "an alignment of the will, a resting of the heart" based upon one's commitment forged by their perception of reality and what truly matters (Fowler, 1995, 14).

\section{Conclusion}

As each of us seeks for clarity, alignment, meaning, and connection in our lives, trust and faith can be powerful sources of comfort and assurance - whether within the context of work or as we pursue connection with God (Briskin, 1998). Trust at its highest level enables individuals to devote their efforts to achieving a meaningful goal and empowers an individual to do so with no reservations or doubts. In that same manner, committed faith provides 
assurances of the heart that bring out the best version of oneself and allow others to dedicate their lives to achieving lasting results (Covey, 2004).

Both trust and faith integrate the four elements of TRA - incorporating one's cognitive beliefs about duties owed, applicable expectations about values and norms, and the nature of the relationship; the attitudes, feelings, and emotions that interact with cognition in assessing the degree of personal connection; and the intentions to act based upon one's abilities to control conditions, context, and resources required; and the ultimate actions undertaken that reflect the degree of one's personal commitment and character.

By understanding the nature of trust and faith, individuals and organizations can improve their ability to enhance relationships, achieve worthy purposes, and assist others in the pursuit of virtuous outcomes - and by so doing become more responsible, more effective, and more accountable in a world that is struggling with constant challenges (Anderson, Ndalamba, \& Caldwell, 2017). As individuals move along their own continuum of trust and faith, they enhance the ability to serve others, to better themselves, to make the world a far better place, and to achieve a worthy purpose in life (Frankl \& Wislade, 2014)

\section{References}

Anderson, V., Ndalamba, K. K., \& Caldwell, C. (2017). Social Responsibility in a Troubled World: A Virtuous Perspective. International Journal of Public Leadership, 13(2), 98-115. https://doi.org/10.1108/IJPL-10-2016-0034

Ashworth, B. E., Schinoff, B. S., \& Rogers. K. M. (2016). 'I Identify with Her,' 'I Identify with Him,': Unpacking the Dynamics of Personal Identification in Organizations. Academy of Management Review, 41(1), 28-60. https://doi.org/10.5465/amr.2014.0033

Bandura, A. (1982). Self-Efficacy Method in Human Agency. American Psychologist, 37, 122-147. https://doi.org/10.1037/0003-066X.37.2.122

Bowker, J. (2006). World Religions: The Great Faiths Explored and Explained. New York: DK Publishing.

Briskin, A. (1998). The Stirring of the Soul in the Work Place. San Francisco, CA: Berrett-Koehler.

Brockner, J., Siegel, P. A., Daly, J. P., Tyler, T., \& Martin, C. (1997). When Trust Matters: The Moderating Effect of Outcome Favorability. Administrative Science Quarterly, 42(3), 558-583. https://doi.org/10.2307/2393738

Burke, P. J. \& Stets, J. E. (2009). Identity Theory. Oxford, UK: Oxford University Press. https://doi.org/10.1093/acprof:oso/9780195388275.001.0001

Caldwell, C., Davis, B., \& Devine, J. A. (2009). Trust, Faith, and Betrayal: Insights from Management for the Wise Believer. Journal of Business Ethics, 89(1), 103-114. https://doi.org/10.1007/s10551-008-9689-0

Caldwell, C., Guevarra, L., Licona, B., Tayor, T., \& McConkie, M. (2013). Trust, Faith, and Fear: Moral Development Applications for Leaders and for Life. Journal of Advanced Management and Business Research, 1(1), 1-15.

Covey, S. R. (2004). The $8^{\text {th }}$ Habit: From Effectiveness to Greatness. New York: Free Press.

DePree, M. (2004). Leadership is an Art. New York: Crown Publishing. ew York: Routledge.

Frankl, V. E., \& Winslade, W. J. (2014). Man's Search for Meaning. Boston, MA: Beacon Press.

Fukuyama. (1996). Trust: The Social Virtues and the Creation of Prosperity. New York: Free Pr

Fishbein. M. \& Ajzen, I. (2015). Predicting and Changing Behavior: The Reasoned Action Approach. N ess.

Gullett, J., Canuto-Carranco, M., Brister, M., Turner, S., \& Caldwell, C. (2009). The Buyer-Supplier Relationship: An Integrative Model of Ethics and Trust. Journal of Business Ethics, 90(3), 329-341. https://doi.org/10.1007/s10551-010-0430-4

Hale, J. L., Householder, B. J., \& Greene, K. L. (2002). The Theory of Reasoned Action in J. P. Dillard \& M. W. Pfau (Eds.). The Persuasion Handbook: Developments in Theory and Practice. Thousand Oaks, CA: Sage, pp. 259-286. https://doi.org/10.4135/9781412976046.n14

Hayes, L. A., \& Caldwell, C. (2016). Self-Efficacy and Self-Awareness: Moral Insights to Increased Leader Effectiveness. Journal of Management Development, 35(9), 1163-1173.

Hosmer, L. T. (1995). Trust: The Connecting Link Between Organizational Theory and Philosophical Ethics. Academy of Management Review, 20(2), 379-403. 
Jones, B. (2017). Finding Faith: Gaining Trust in God. Los Angeles, CA: Universal Spirit Press.

Kramer, R. M., \& Tyler, T. (1996). Trust in Organizations: Frontiers of Theory and Research. Thousand Oaks, CA: Sage.

Kurland, N. B. Ethical Intentions and the Theories of Reasoned Actions and Planned Behavior. Journal of Applied Social Psychology, 24(4), 297-313.

Kushner, H. S. (2001). Living a Life that Matters. New York: Anchor Books.

Malloch, T. R. (2006). Spiritual Enterprise: Doing Virtuous Business. New York: Encounter Books.

Mele, D. (2009). Business Ethics in Action: Seeking Human Excellence in Organizations. New York: Palgrave MacMillan. https://doi.org/10.1007/978-1-137-07468-3

Mele, D. (2012). Management Ethics: Placing Ethics at the Core of Good Management. New York: Palgrave MacMillan. https://doi.org/10.1057/9780230361560

Tilley, T. W. (2010). Faith: What It Is and What It Isn't. New York: Orbis Books.

Verhagen, T., Meents, S., \& Tan, Y-H., (2006). Perceived Risk and Trust Associated with Purchasing at Electronic Marketplaces. European Journal of Information Systems, 15(6), 542-555. https://doi.org/10.1057/palgrave.ejis.3000644

Vlaar, P. W. L., van den Bosch, F. A. J., \& Volberda, H. W. (2007). On the Evolution of Trust, Distrust, and Formal Coordination and Control in Interorganizational Relationships: Toward an Integrative Framework. Group \& Organization Management, 32(4), 407-429. https://doi.org/10.1177/1059601106294215

Watson, T. (2013). The Doctrine of Repentance. Pensacola, FL: Chapel Library. 